\title{
Understanding the structural concept of the design of the Winter Garden at the Royal Glasshouses of Laeken (Brussels, Belgium) by three-dimensional structural analysis
}

\author{
L. Lauriks, M. de Bouw \& I. Wouters \\ Department of Architectural Engineering, Vrije Universiteit Brussel, \\ Belgium
}

\begin{abstract}
The Winter Garden (1874-1876) is part of the major complex of the Royal Glasshouses of Laeken, situated at the north of Brussels, Belgium. As part of the ongoing renovation study, we want to have an insight into the structural concept of the iron frame. There are two different viewpoints on the structural design of this impressive glasshouse by Alphonse Balat. This paper examines the structural concept by calculations of three-dimensional models of the iron frame in a finite elements software package.
\end{abstract}

Keywords: Winter Garden, Balat, Brussels, glasshouse, Vierendeel, dome, structural concept, iron, glass.

\section{Building the Winter Garden}

\subsection{The Royal Glasshouses of Laeken}

The Royal Domain of Laeken, situated at the north of Brussels, is one of the residences of the Belgian royal family. The Royal Palace was built in 1781 stimulated by the Governors-General of the Austrian Netherlands. It was expanded with an orangery in 1818 and a complex of glasshouses from 1874 until 1905. The complete set of glasshouses takes up an area of 1.5 ha, covered with 2.5 ha of glass (Goedleven [1]). All entities were built between 1818 and 1905 in order of king Leopold II. Alphonse Balat ( $\left.{ }^{\circ} 1818+1895\right)$ was the architect of the majority of these Royal Glasshouses. After his death, the 


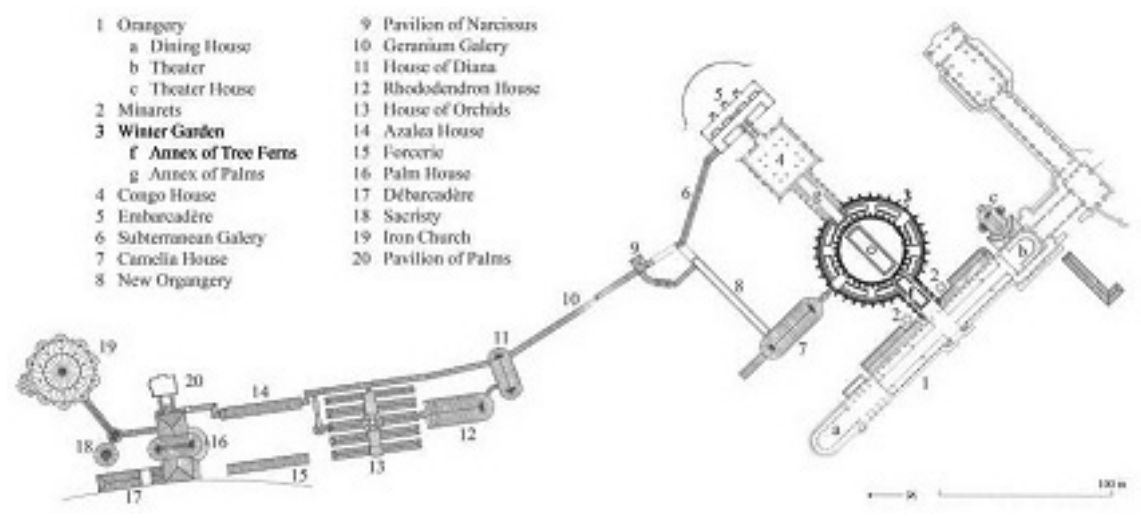

Figure 1: $\quad$ Map of the Royal Glasshouses of Laeken (Koppelkamm [2]).

complex was finished by architects Henri Maquet and Charles Girault. In 1895, landscape architect E. Lainé layed out a new park around the glasshouses.

The shape of the glasshouses is related to their function. The plants for the park, for the glasshouses and for the decorations of the Royal Palace are cultivated in culture houses like the Camelia House and the Azalea House (glasshouse $\mathrm{n}^{\circ} 7$ and $\mathrm{n}^{\circ} 14$ on Figure 1). Some other glasshouses are used by the royal family for social and political events, like the Winter Garden and the Diana House (glasshouse $\mathrm{n}^{\circ} 3$ and $\mathrm{n}^{\circ} 11$ on Figure 1). Through the years, the function of some glasshouses changed, others were demolished or rebuilt. The Winter Garden kept his function as a showpiece.

Among the complex of the glasshouses, the most striking one is the Winter Garden, built between 1874 and 1876 by the royal architect Alphonse Balat under the authority of king Leopold II (glasshouse $\mathrm{n}^{\circ} 3$ on Figure 1). The Winter Garden is a significant cultural legacy and an important witness of the evolution of structural ironwork and Art Nouveau in Belgium. It is the first glasshouse on the Royal Domain with a complete iron frame and glass covering.

Every year around May, the Royal Glasshouses are open to the public and thousands of people are attracted to admire the extensive plant collection and the architectural masterpieces of the 19th century.

\subsection{The design of the Winter Garden}

The Winter Garden is constructed by 36 arch trusses which are rotated around a central point, thus forming one large dome. The arch trusses are divided in two main parts by the glass covering (Figure 2). The first part consists of the dome in the middle of the glasshouse, topped off with a small cupola and a royal crown. The second part is a side aisle around the middle dome. These two parts are separated by a circular architrave on sandstone columns (Figure 3).

The middle dome of the Winter Garden is 41,25 meter in diameter and 25,65 meter high (excluded the height of the royal crown), surrounded by the 7,94 meter wide and 9,05 meter high side aisle. 


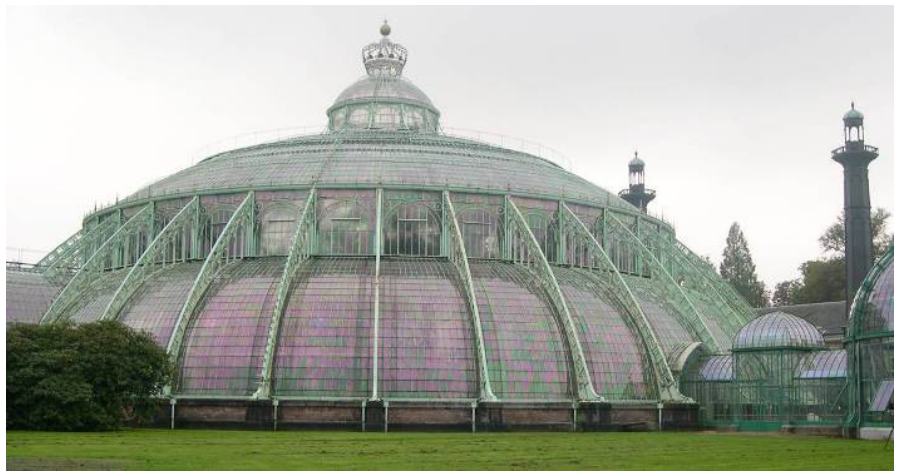

Figure 2: $\quad$ Side view of the Winter Garden.

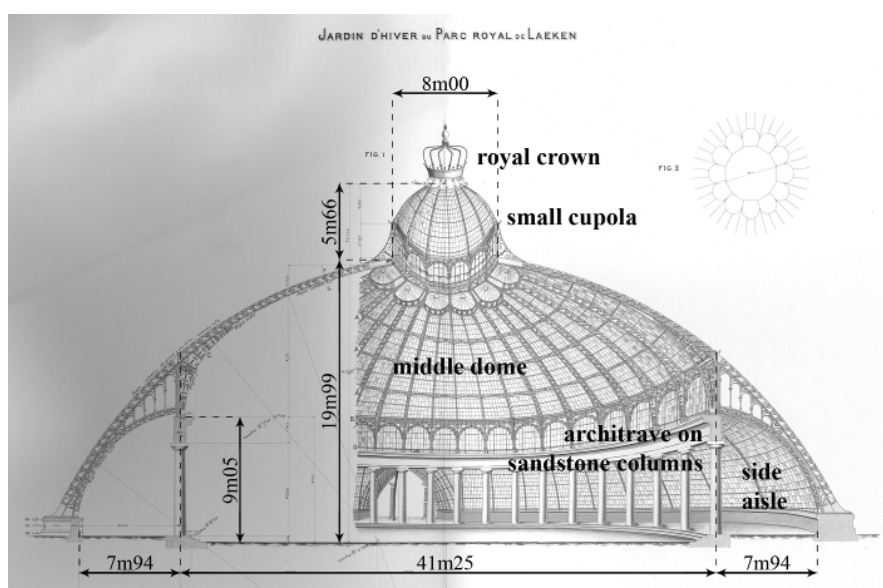

Figure 3: $\quad$ Section of the Winter Garden (Vierendeel [3]).

Engineer and Professor Arthur Vierendeel $\left({ }^{\circ} 1852\right.$ †1940) describes the structural concept of the iron frame of the Winter Garden in his book La construction architecturale en fonte, fer et acier from 1902 (Vierendeel [3]). He says that the middle dome is structurally independent from the side aisle. The tension ring at the base of the middle dome absorbs all the lateral arch thrusts. The forces are further guided to the foundation work through the sandstone columns. All literature about the Winter Garden refers to the above-mentioned book when citing this structural concept explained by Vierendeel. George Nieuwmeijer $\left({ }^{\circ} 1945+2008\right)$, former engineer and professor at TU Delft, gives another argument sustaining this concept (Nieuwmeijer [4]). The outer arch of the side aisle is the only part of the structure which is not supported against buckling out of plane, in the direction of the minor axis of inertia. This argument states that the outer arch cannot withstand high loads so the main load-bearing structure for the lateral arch thrusts has to be the tension ring at the base of the middle dome. 
Another approach on this topic concerns a comparison with other glasshouses of the $19^{\text {th }}$ century in Europe. For the design of the Winter Garden, Alphonse Balat referred to the Palm House (Kew Gardens, London, 1844-1848) designed by Decimus Burton and Richard Turner. Balat used the structural concept of the Palm House for his Winter Garden (Vandewoude et al. [5]) and applied this to a circular ground plan. The design of the Palm House in its turn was inspired by the Great Conservatory (1836-1840) of Joseph Paxton which was unfortunately demolished in 1920. When looking at the sections of these three glasshouses, the concept of the bearing structure of the Winter Garden seems a copy of the other two but with the addition of the outer arch (Figure 4).

People would intuitively feel that cupola geometry produces lateral thrusts. The viewer was not yet visually acquainted with the very thin innovative iron constructions emerging at that time. It is thus generally felt as an aesthetically more beautiful construction when there is a visually identifiable structural part that can withstand these thrusts. The question arises whether architect Alphonse Balat added the outer arch of the side aisle solely to ease the viewer's mind?
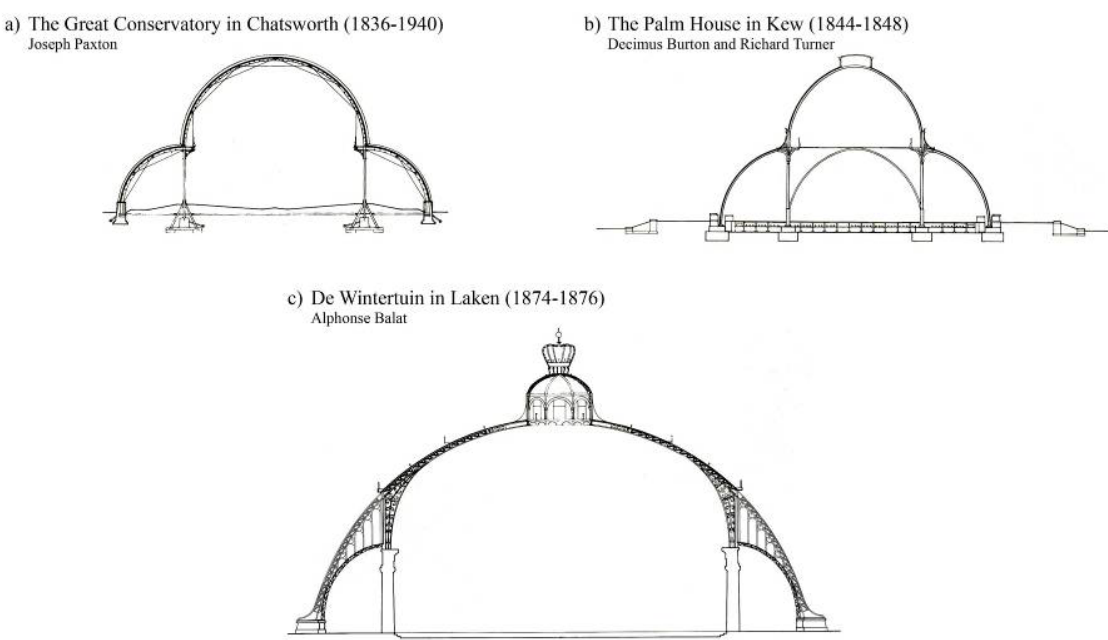

Figure 4: $\quad$ Sections of historic glasshouses (Kohlmaier and Von Sartory [6]).

\subsection{The Winter Garden today}

The iron structure of the Winter Garden is mostly unchanged, compared to the original construction dating back to 1876 . Therefore, great historical value is attached to this building and any future restorations have to be done with the greatest respect to the original structure, although it is not listed as a historical building.

For a detailed description of the present state of the construction, we refer to the author's paper Structural assessment of the Winter Garden of the Royal Glasshouses of Laeken, Belgium (Lauriks et al. [7]). In the years 1970, the 
Winter Garden received some small refurbishments and in the 1980's a major restoration was carried out, funded by the owner Regie der Gebouwen. The small glass panes were replaced and the joints between the plates were filled with mastic. The iron sections were sand-blasted, repaired if necessary and repainted. At this moment, only 20 years later, a second major restoration campaign is being prepared because of the excessive corrosion problems.

\section{Structural analysis of the Winter Garden}

To check the statement of Vierendeel, who claims that the outer arch of the side aisle does not have a structural role, we model the load bearing structure without this outer arch and check whether it can stand the loads. The results are compared to the actual model, with the outer arch.

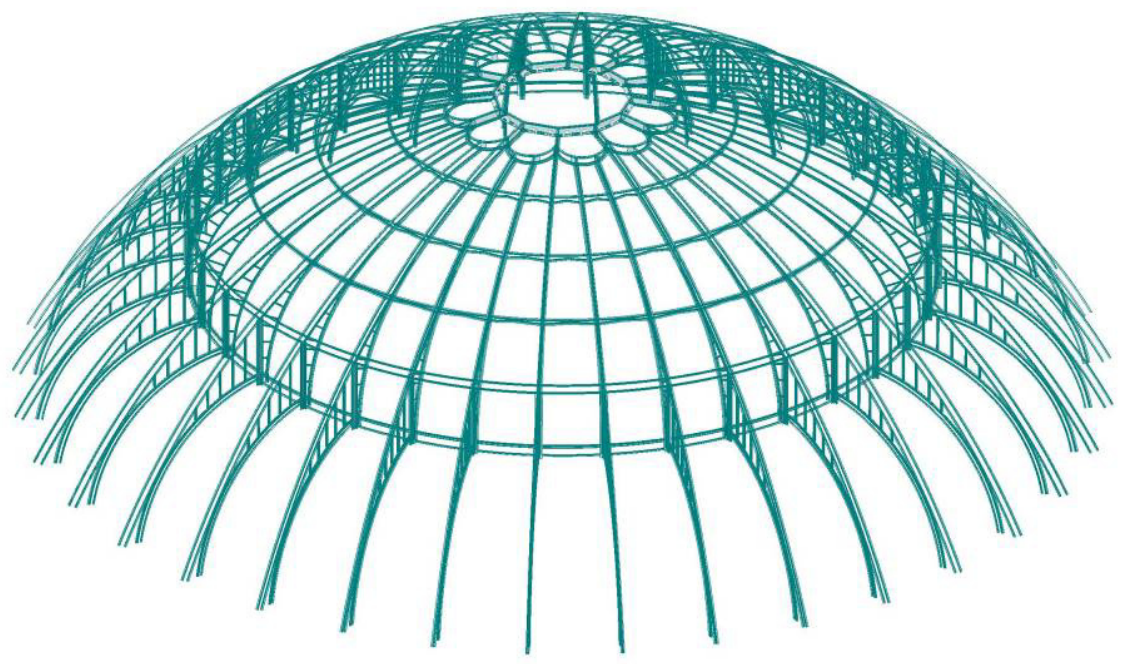

Figure 5: Complete model of the iron frame of the Winter Garden.

\subsection{Building the three-dimensional model}

The complete three-dimensional model consists of 36 trusses each built up of 11 different sections. The side aisle contains an outer arch, an inner arch and vertical bars connecting these two. The middle dome starts with a column at the intersection with the side aisle. At the base of this column starts a lower arch which is converging to an upper arch running from the top of the column to the centre of the dome. Bars are connecting this upper and the lower arch. In the radial direction, the 36 arches are connected with concentric rings: one at the base and one at the top of the column, three intermediate rings and finally a ring at the top shaped like multiple petals (Figure 5). 
The first model, we will call it the complete model, is an approximation of the real structure. A second model was made by omitting the outer arch of the side aisle and the bars connecting it with the inner arch. We refer to this model in the text as the Vierendeel model. All calculations are made in a finite elements software package (SCIA [8]).

The self weight, the snow load and the wind action are the considered loads on the structure. The self weight is determined by the density of the iron, but also by the weight of the glass covering, the glazing bars, the decoration elements, etc. The snow load can be symmetric or asymmetric due to the distribution of the snow layer under wind action (Eurocode 1 [9]). The snow load can increase locally by accumulation of the snow at the vertical transition planes due to wind drift and snow sliding down from the upper areas. The wind load is calculated using the methods of the Eurocodes by approaching the geometry of the Winter Garden with the assembly of basic geometrical shapes, cylinders and spherical domes, defined in the codes (Eurocode 1 [10]).
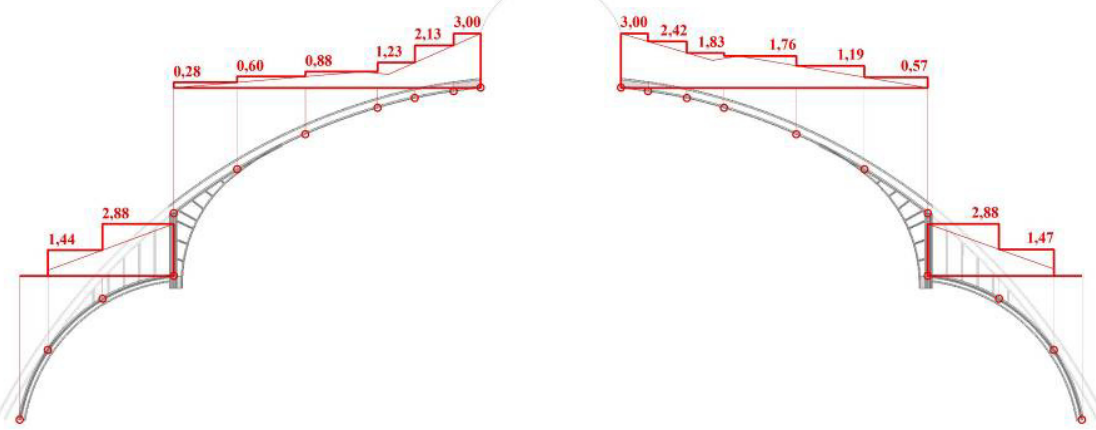

Figure 6: Applied snow load on the structure $\left[\mathrm{kN} / \mathrm{m}^{2}\right]$.

\subsection{Results of the three-dimensional analysis}

The first calculation of the three-dimensional complete and Vierendeel model revealed that one particular load case is determinant: the combination of the self weight and the asymmetric snow load with accumulation at the vertical transition planes. The values of that snow load are graphically represented in Figure 6. We will restrict the discussion of the results in the next paragraph to the combinations of this snow load and the self weight in ultimate limit state - ULS (eqn. 1) and serviceability limit state - SLS (eqn. 2).

$1,35 *$ self weight $+1,50 *$ asymmetric snow load with accumulation

$1,00 *$ self weight $+1,00 *$ asymmetric snow load with accumulation

To understand how forces are running through both structural models, we present the analytical results of the calculations by means of comparative diagrams. Although it is not the focus of the paper, it is important to mention that the stress levels do not exceed the allowable stress of the historic iron, the 
deformations do not exceed the allowable displacements stated in the Eurocodes for structures with a covering in a brittle material and no stability problems arise under the applied loads.

\subsection{The load distribution in the complete and the Vierendeel model}

At the start we were interested in the following questions:

- Can the structure without the outer arches of the side aisle withstand the loads?

- By adding the outer arches of the side aisle, the forces in the middle dome will decrease, but to what extent and how does this affect the supports?

- To what extent will the stresses in the sections of the side aisle and the middle dome change when adding the outer arches of the side aisle?

To discuss the results, we will present a section through the most heavily loaded truss in the three-dimensional model.

The upper diagram in Figure 7 shows the deformations in SLS of the complete model subjected to the combination of the self weight and the
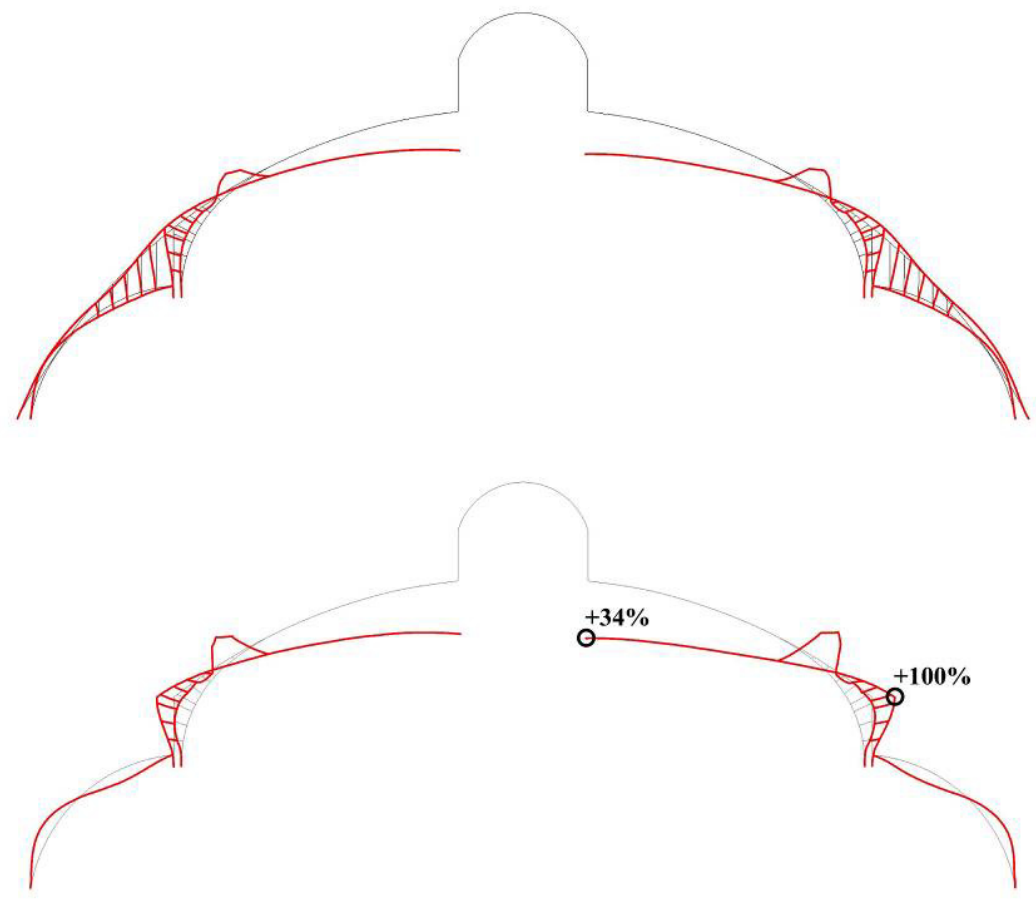

Figure 7: Deformation of complete (above) and Vierendeel (below) model in SLS. 
asymmetric snow load with accumulation at the vertical transition planes. The lower diagram shows the deformations under the same load conditions for the Vierendeel model. Taking the upper diagram as a reference, we mention the decrease and increase of the deformation in percentages.

The two diagrams in Figure 7 clearly show the zone influenced by deleting the outer arch of the side aisle. When deleting the outer arch, the middle dome becomes an independent structure. The horizontal deformation of the arch of the middle dome at the intersection point with the deleted outer arch will double $(+100 \%)$. However, the influence decreases while approaching the centre of the dome.

We can conclude that deleting the outer arch and the bars connecting it with the inner arch makes the structure less stiff but this has a limited area of influence.

Figure 8: shows the Von Mises stresses and reaction forces in the ULS combination of the self weight and the asymmetric snow load. In the lower diagram, the percentages at the left side concern the stresses in the concentric rings (which are out of plane of the diagram).

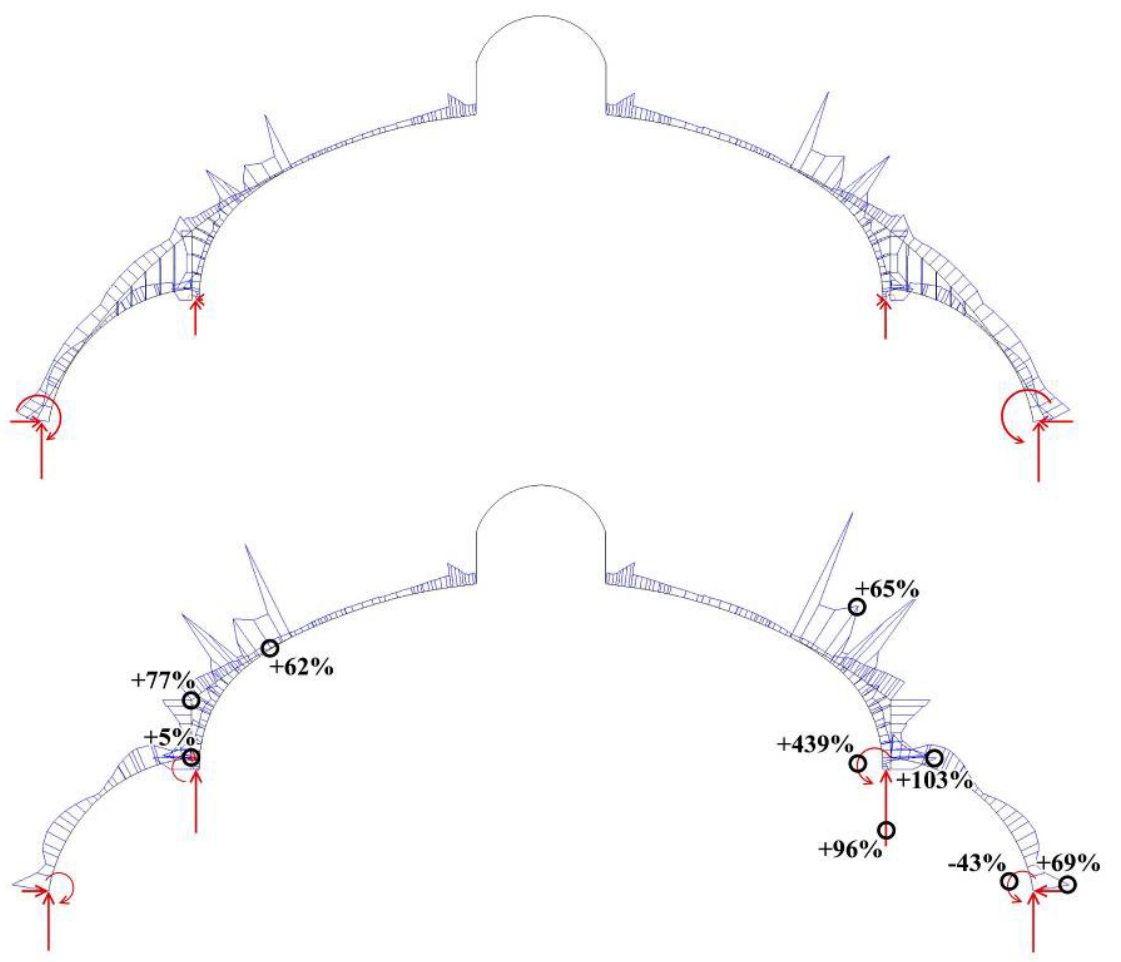

Figure 8: $\quad$ Von Mises stresses and reaction forces of complete (above) and Vierendeel (below) model in ULS. 
The diagrams clarify how the thrust forces are distributed when the outer arch of the side aisle is omitted. The stresses in the concentric ring at the top of the column increase by $77 \%$, thus act as an important thrust tension ring. The stresses at the lower arch of the middle dome and at the intermediate concentric ring next to the column ring are also augmenting (resp. with 65 and 62\%). The columns $(+103 \%)$ as well as their supports $(96 \%)$ take up the vertical loads. The stresses in the inner arch of the side aisle raise with $69 \%$ when the outer arch is deleted, thus stating that in the complete model, the outer arch plays an important role in taking up the loads on the glass surface. For the elements further away from the outer arch of the side aisle, the influence of deleting it diminishes.

Despite the raise of the deformations and the stresses in the Vierendeel model, the levels are still allowable (within the limitations of this model). The structure without the outer arch of the side aisle is able to withstand the loads without exceeding the allowable stress level and deformations.

Putting it the other way around, we can state that the outer arch decreases the stress levels and deformations, giving the structure additional strength and safety. The structure might stand for example a raise of the self weight when replacing parts of the glazing by laminated glass. Or a weakened truss of the middle dome has the possibility to transmit his forces to the outer arch of the side aisle.

\section{Conclusion}

Architect Alphonse Balat based the design of the Winter Garden on two other glasshouses, the Palm House in Kew and the Great Conservatory in Chatsworth. This reference throws up the question about the structural role of the outer arch of the side aisle of the Winter Garden, which was not present at the two referenced glasshouses.

The calculations showed that the structure without the outer arch of the side aisle can withstand the forces. Nevertheless, the stresses in the complete model are more evenly spread. The outer arch serves as a kind of backup structure for the other surrounding elements, which must be exploited when renovating the structure.

\section{Acknowledgements}

This research was funded by the Institute for the Promotion of Innovation by Science and Technology in Flanders (IWT-Vlaanderen).

\section{References}

[1] Goedleven, E., De Koninklijke Serres van Laken, Lannoo: Tielt, 1988.

[2] Koppelkamm, S., Glasshouses and Wintergardens of the Nineteenth Century, Granada: Berlin, pp. 90-97, 1988. 
140 Structural Studies, Repairs and Maintenance of Heritage Architecture XI

[3] Vierendeel, A., La construction architecturale en fonte, fer et acier, Uystpruyst: Leuven, 1902.

[4] Nieuwmeijer, G., Plantenkassen: van plompe constructies tot de glazen stad van Laken. Het Ingenieursblad, 1992 (11), pp. 31-38, 1992.

[5] Vandewoude, E., De bouw van de Wintertuin te Laken, 1874-1876, een initiatief van Leopold II. Album Carlos Wyffels, Algemeen Rijksarchief: Brussels, pp. 457-473, 1987.

[6] Kohlmaier, G. \& Von Sartory, B., Houses of glass: a nineteenth-century building type, MIT: Cambridge, 1991.

[7] Lauriks, L., Wouters I., Adriaenssens, S., de Bouw, M., Verbeeck, B., Structural assessment of the Winter Garden of the Royal Glasshouses of Laeken, Belgium. Proc. of Int. Conf. on Structural Analysis of Historical Construction, eds.: D. D'Ayala, E. Fodde, Taylor \& Francis Group: London, pp. 683 - 688, 2008.

[8] SCIA Engineer, release 2008.1, Scia Group nv: Herk-de-Stad, 2008.

[9] NBN EN 1991-1-3, Eurocode 1: Belastingen op constructies - Deel 1-3: Algemene belastingen - Sneeuwbelasting, October 2003.

[10] NBN EN 1991-1-4, Eurocode 1: Belastingen op constructies - Deel 1-4: Algemene belastingen - Windbelasting, October 2005. 